\title{
GeOmorphic And Sedimentological Controls on HyPORHEIC FlOW IN AN Alpine River
}

Undergraduate Research Thesis

Submitted in partial fulfillment of the requirements for graduation with research distinction in Earth Sciences

in the undergraduate colleges of

The Ohio State University

By

Kira D. Harris

The Ohio State University

2020 
Approved by



Audrey Sawyer, Advisor School of Earth Sciences 


\section{TABLe OF Contents}



Acknowledgements.................................................. ii



List of Tables.......................................................... vi





Methods

Sediment Collection............................................... 3

Sediment Analyses.................................................4

Vertical Head Gradient Measurement.............................4

Ground-Penetrating Radar Collection............................4

Results

Grain Size Analysis.............................................. 6

Ground Penetrating Radar Analysis............................ 9

Potential for Vertical Flow........................................9

Discussion.............................................................. 12

Conclusions.......................................................... 13

Recommendations for Future Work..................................14

References Cited...................................................... 15

Appendix.............................................................. 17 


\section{ABSTRACT}

The hyporheic zone, where surface water enters the riverbed and mixes with groundwater, affects surface water quality. Variations in streambed morphology and sediment characteristics in meandering rivers lead to heterogeneity in hyporheic exchange, with flow paths that range in scale from centimeters to hundreds of meters. To assess controlling factors for hyporheic exchange in a 200-m reach of a meandering alpine river, forty-three sediment samples were analyzed for grain size in East River, Colorado (USA). Additionally, vertical hydraulic head gradients were measured at eighty locations. A ground-penetrating radar survey was also used to characterize streambed morphology. In this predominantly gravel stream, the meander and pool-riffle morphology control large-scale patterns of hyporheic flow, while variations in grain size and permeability appear to play a smaller, modifying role. These results will improve flow and reactive transport models over dynamic flood and base flow conditions at the intensively studied field site and improve the understanding of the interplay between hyporheic flow and streambed characteristics. 


\section{ACKNOWLEDGEMENTS}

The breadth of experiences that I have had in my undergraduate career in the School of Earth Sciences at The Ohio State University has helped shape my passion for learning about the natural world into a pursuit of an academic research career.

First, I would like to thank Amelia Nelson for taking me on as a field assistant during my sophomore year. We took hundreds of streambed temperature measurements, hundreds of hand-filtered water samples, hammered steel pipes into the streambed in over 90 locations, had 4 or 5 temperature data loggers' cords chewed by cows, and drove over 40 cumulative hours across the United States, all in less than a month. This was a massive formulating experience that continues to help mold me into the scientist I am today. I would also like to thank Amelia for all the poster edits, graduate school application edits, and for being an amazing mentor and friend. I would not be where I am today without her guidance and support.

Second, I'd like to thank Dr. Audrey Sawyer for her willingness for her graduate students to take on undergraduate assistants. This in turn gave me the opportunity to become part of the whole lab group, which has been incredibly useful and important part of my research experience and my graduate school preparation. Dr. Sawyer's knowledge and guidance have helped propel me into the world of geologic research, while also exemplifying a successful woman in academia that I aspire to be. I greatly appreciate both her and Amelia's mentorship, especially as a first-generation college student.

Third, I'd also like to thank previous and current students of Dr. Sawyer's lab group: Alex Brown, Savannah Bryant, Jacob Clyne, Deon Knights, and Karl Wilhelmsen, and Dr. Michael Wilkins' graduate student Casey Saup for poster and thesis revisions, grain size analysis and loss on ignition help, and the countless answered questions.

Next, I would like to thank Dr. James St. John at The Ohio State University Newark Campus for introducing me to the geology of Ohio. His willingness to take students out in the field outside of class based on their interest is what brought me into this major, and I hope that I can replicate his drive for teaching Earth sciences in my own classroom one day. Thank you to Jason Cervenec for hiring me as an Education and Outreach intern at the Byrd Polar and Climate Research Center. My work at the Byrd Center allowed me to present outreach activities at professional conferences alongside Earth science research and develop my love for outreach and science communication. Thank you to all the faculty and staff that help make it the coolest place to work on campus!

I would also like to thank the people outside of Ohio State who supported me. My father, for asking clarifying questions and being proud of me no matter what. My mother, for her unconditional support and lunch dates for school supplies. My grandmother, for always making sure I was taking care of myself and supporting me in more ways than one. Finally, my boyfriend Bryan Justice, for being there during my entire undergraduate journey. There isn't a 
better way to get through the ups and downs of higher education than with your best friend by your side.

I'd like to thank The Shell Exploration and Production Company for my initial research experience with Dr. Ian Howat on the behavior of Greenland's outlet glaciers. Thank you to the Friends of Orton Hall Fund and the McKenzieBrecher Scholarship for providing funding for me to travel to professional conferences. I would also like to thank the William J. Buschman Scholarship in Earth Sciences, The Marcus J. and Lottie C. Lieberman Scholarship, and the Central Ohio Mineral, Fossil, Gem \& Jewelry Show Scholarship for helping support my undergraduate education.

Finally, this work was supported as part of the U.S. Department of Energy Watershed Function Scientific Focus Area under Award DE-SC0016488 to Dr. Michael Wilkins and Dr. Sawyer. Thank you to Dr. Daniel Pradel of Ohio State Civil, Environmental, and Geodetic Engineering for use of the CTL Laboratory for sediment analyses. Thanks also to the U.S. Geological Survey Hydrogeophysics Branch, specifically Marty Briggs, Eric White, and John Lane, for their GPR data collection and post-processing. Thanks also to the Rocky Mountain Biological Laboratory for lodging and Dr. Ken Williams for laboratory space during the field campaign. 


\section{LIST OF FIgURES}

1. Site Description

2. Sampling Locations

3. Ground-Penetrating Radar Type Section

4. Cumulative Percent Finer Than Curves

5. Histograms of $\mathrm{D}_{10}$ and Loss on Ignition

6. Spatial Distribution of $\mathrm{D}_{10}$ and Loss on Ignition

7. Loss on Ignition versus $\mathrm{D}_{10}$

8. Spatial Distribution of Depth and Amplitude

9. Amplitude versus Grain Size Properties

10. Vertical Head Gradient versus $\mathrm{D}_{10}$

11. Spatial Distribution of Vertical Head Gradient 


\section{INTRODUCTION}

River water and groundwater quality are affected by microbial and geochemical processes that take place in the hyporheic zone, a transition zone between surface water and groundwater (Boulton et al., 1998; Sinsabaugh and Findley, 1995). River water downwells into the bed and recharges aquifers through the hyporheic zone. Groundwater upwells through the hyporheic zone and contributes to flow in the river (Winter, 1998). The hyporheic zone removes metals by sorption (Nagorski and Moore, 1999; Saup et al., 2017), acts as a sink for phosphorous and nitrogen (Harvey et al., 2013), and is a location for microbial metabolism of organic matter (Ruhala et al., 2018; Stegen et al., 2016).

Hyporheic flow is affected by the sediment properties of the bed, especially permeability and porosity, and by morphology. Small- and large-scale morphologic features in a streambed create gradients in hydraulic head due to interactions with currents (Boano et al., 2006; Kiel and Cardenas, 2014). Morphologic features that drive flow include gravel bars, ripples (Cardenas and Wilson, 2007), pool-riffle sequences (Harvey and Bencala, 1993; Tonina and Buffington, 2007), and meanders (Cardenas at el., 2008; Wondzell, 2006). Computer models of hyporheic exchange are increasingly able to resolve smallscale variations in sediment properties (Cardenas, 2004; Engdahl, 2010) and morphology (Stonedahl et al., 2010; Chow et al., 2018) but mapping them remains a time and labor-intensive process.

The goal of this study was to characterize streambed physical properties, morphology, and the vertical head gradients that drive hyporheic exchange in an alpine stream. The site lies within the East River Watershed Function Science Focus Area in Colorado, USA (Figure 1). Forty-three sediment grab samples were collected from a meandering reach of the river in order to characterize grain size distributions across the streambed. Grain size data were integrated with manual measurements of vertical hydraulic head gradient and ground-penetrating radar (GPR) surveys to explore relationships among grain size, bed morphology, and the potential for vertical water exchange. We show that grain size distribution tends to be coarser in the thalweg of the channel, particularly near a large pool within the reach, and less coarse along the edges of the channel, particularly near the point bar of the meander. The patterns of vertical hydraulic head gradient are complex and appear to be influenced by morphologic features such as the meander and pool-riffle transitions and possibly variations in sediment texture. 


\section{Study ARea}

The study site lies in the East River watershed in central Colorado, USA

(Figure 1). This alpine watershed ranges in elevation from $2445 \mathrm{~m}$ to $4100 \mathrm{~m}$. Snowmelt is the dominant source of annual runoff. Average monthly streamflow rates range from $36.65 \mathrm{~m}^{3} / \mathrm{s}$ in the peak snowmelt season (June) to $1.61 \mathrm{~m}^{3} / \mathrm{s}$ in January at USGS Station $09112200,25.4 \mathrm{~km}$ downstream of site. The watershed predominantly includes forested areas with rangeland, although the Mt. Crested Butte town is experiencing an increase in urban development associated with recreational activities and tourism.

The study site's 200 m-long meander is located within the U.S. Department of Energy-supported Lawrence Berkeley National Laboratory's Watershed Science Focus Area, just downstream of the Pumphouse, an intensively studied site at $38.922245^{\circ} \mathrm{N},-106.950650^{\circ} \mathrm{W}$. The meander has an average channel gradient of $0.01 \mathrm{~m} / \mathrm{m}$, an average channel width of $8 \mathrm{~m}$, and flow depths ranging from 3 $\mathrm{cm}$ in the riffles to greater than $1 \mathrm{~m}$ in pools at baseflow. The reach is underlain by Cretaceous Mancos shale (Nelson et al., 2019).

This study was part of a broader project to understand the microbiology and biogeochemistry of hyporheic water within a meandering alpine river. Details on pore water chemistry and microbial community composition are available in Nelson et al. (2019).



Figure 1: Map of the East River running from northwest to southeast near Crested Butte, CO, USA. Inset shows meander at focus of study $\left(38.922245{ }^{\circ} \mathrm{N},-106.950650\right.$ $\left.{ }^{\circ} \mathrm{W}\right)$. A-A' is location of GPR type-section in Figure 3. 


\section{MethOdS}

Sediment Collection. Forty-three sediment samples were collected during August 1 -August 13, 2018 at locations corresponding to pore water sampling locations described in Nelson et al. (2019) (Figure 2). The sediment grab samples were collected using a standard shovel, retrieving the top 5-8 cm of sediment. Each sediment sample was collected approximately $30 \mathrm{~cm}$ upstream from each pore water sampling location so that sediment collection avoided disturbing hyporheic flow and chemistry. Grab samples were not taken in locations with cobbles and boulders larger than $8 \mathrm{~cm}$ in diameter, as these samples were deemed too coarse to analyze accurately with standard sieving techniques. Samples were double-bagged in Whirly bags and kept refrigerated at the Rocky Mountain Biological Laboratory until the end of the field campaign. Samples were then placed in chilled coolers to be transported to The Ohio State University where they were again kept refrigerated for 1 to 4 weeks before analysis.



Figure 2: Vertical head gradient (VHG) and sediment sampling locations (modified from Nelson et al., 2019).

Sediment Analyses. Sediment samples were removed from the refrigerator and spread onto plastic trays to air dry for at least 24 hours. Once dry, clumps of fine sediment were broken up and the sample was separated into four equal 
parts. One-fourth of the sample was combusted at $550{ }^{\circ} \mathrm{C}$ for 4 hours to determine loss on ignition (LOI), a measure of organic matter (OM) content in the sample, according to ASTM D. 2974-87. LOI was calculated as:

$100 \%$ - ((100 - Weight in ash (g)) / Dry weight (g))

The remaining three-fourths of the sample were wet sieved to $63 \mu \mathrm{m}$. The water containing fines $(<63 \mu \mathrm{m})$ was collected in $1000 \mathrm{~mL}$ graduated cylinders and topped with water to a volume of $1000 \mathrm{~mL}$. The water was thoroughly mixed for 30 seconds and a $5 \mathrm{~mL}$ pipette was used to extract a total of $20 \mathrm{~mL}$ from the $750 \mathrm{~mL}$ mark on the cylinder. This $20 \mathrm{~mL}$ sample was placed on a pre-weighed aluminum weigh boat and dried at $105{ }^{\circ} \mathrm{C}$ for at least 12 hours to evaporate the water. The boat was then weighed to determine the mass contribution of mud $(<63 \mu \mathrm{m})$ to the sample, specifically:

Mud mass $=($ Dried tin weight $(\mathrm{g})-$ Empty tin weight $(\mathrm{g})) * 50$

The coarse fraction (> $63 \mu \mathrm{m}$ ) remaining after wet sieving was dried at $105{ }^{\circ} \mathrm{C}$ for at least 12 hours to evaporate the water. It was then dry sieved according to ASTM C136/C136M-14. More details on the grain size and LOI procedure are available in the Standard Operating Procedure in Appendix A.

Ground-Penetrating Radar Collection. Ground-Penetrating Radar (GPR) surveys were performed by USGS scientists during August 5 - August 7, 2018. GPR antennae with $450 \mathrm{MHz}$ center frequency and a differential Global Positioning System (GPS) were housed in a plastic floating container that was moved along transects. Eight transects were performed across the channel, and one longitudinal survey was performed along the channel thalweg in an effort to map water depth (Figure 3). These profiles were collected using an interval of 10 traces per second. Survey data were post-processed by USGS scientists in REFLEXW (Sandmeier, 2019) with a protocol that included a time zero correction and a gain to scale up low amplitudes.

To verify GPR transect locations, I located the water bottom on intersections between transects and adjusted the locations of transects, where needed, to ensure consistent water bottom depths at intersections. I also verified that transect locations fell entirely inside the wetted channel on aerial images. Horizontal shifts of up to $2.5 \mathrm{~m}$ were applied to the GPR transect locations. These shifts were deemed within the error of the enclosed GPS system.

Vertical Head Gradient Measurement. Vertical head gradient measurements were made at each pore water sampling location (Figure 2) using a 1/2" diameter steel pipe that was hammered into the streambed to an approximate depth of $40 \mathrm{~cm}$. Water level was allowed to equilibrate inside the pipe and then measured using a chalked wire. Equilibration times varied from minutes to multiple days depending on location in the meander. 
Vertical Head Gradient $(\mathrm{VHG})=\frac{\text { head difference between standpipe and river }}{\text { depth of standpipe below sediment-water interface }}$

Positive values indicate potential for upward flow (groundwater upwelling) and negative values indicate potential for downward flow (surface water downwelling).



Figure 3: Left: locations of GPR transects throughout the meander. Right: typesection A-A' (colored red at left and shown in Figure 1). 


\section{RESULTS}

Grain Size Analysis. The 43 sediment samples varied in grain size distributions but were overwhelmingly coarse. All samples were classified as gravel on a ternary diagram of gravel, sand, and mud. The $\mathrm{D}_{10}$ values, or the $10^{\text {th }}$ percentile grain diameter, ranged from $0.3 \mathrm{~mm}$ to $19 \mathrm{~mm}$ with a mean of $3.6 \mathrm{~mm}$. (Figure 4, Figure 5A). The spatial patterns of $\mathrm{D}_{10}$ varied throughout the meander, but coarser sediments were generally found near a pool where the channel widens, and finer sediments were found in the meander's apex near the point bar (Figure 6A).



Figure 4: Cumulative grain size distribution curves for each sediment sample. $\mathrm{D}_{10}$ values are represented by the tenth percentile grain diameter, shown with a red-dashed line for one sample. This is interpreted as the grain diameter that only $10 \%$ of the sample is finer than. For some samples, a large portion of the mass was coarser than the largest sieve size $(25.4 \mathrm{~mm})$

Loss on ignition (LOI) was generally small throughout the meander, with a mean of $0.7 \%$ (Figure 5B). Locations with greater LOI were found on edge of the channel or in the bend of the meander, not in the straight portions of the channel (Figure 6B). LOI tended to be greater for finer sediment samples, though a strong relationship was not observed (Figure 7). 



Figure 5: A) Histogram of $\mathrm{D}_{10}$, the tenth grain diameter percentile. Bin separations correspond with sieve sizes used in grain size analysis (Appendix A). $\mathrm{D}_{10}$ values are generally coarse. B) Histogram of LOI frequency. LOI tends to be less than $1.0 \%$ and skewed towards smaller values. 


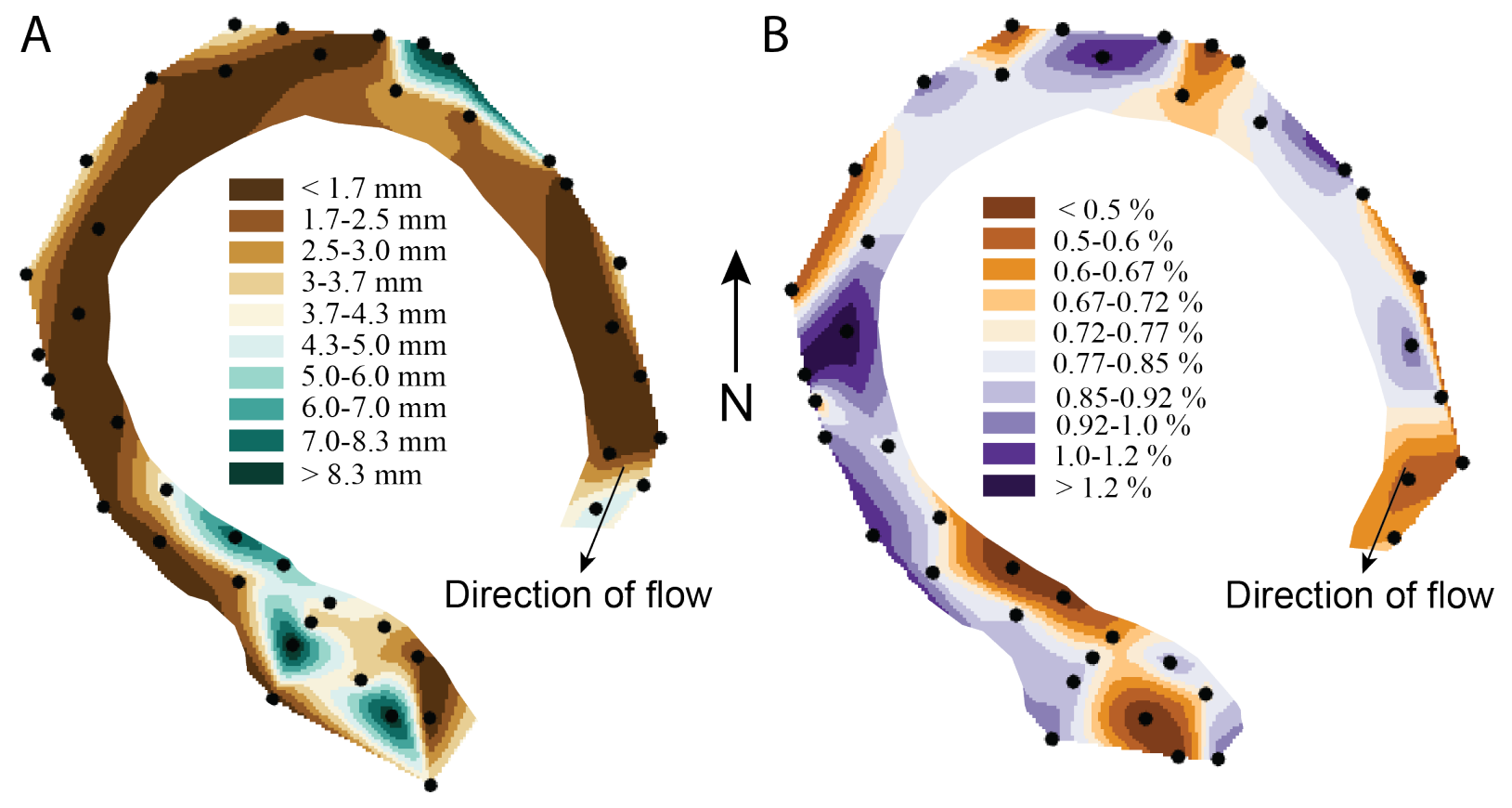

Figure 6: A) Distribution of $D_{10}$ values throughout the meander. Coarser sediments were found in the center of the channel to the south near a large pool and along on the northern edge of the meander in another pool. B) Distribution of LOI values throughout the meander. Smaller LOI values tend to be in areas with coarser grain sizes.

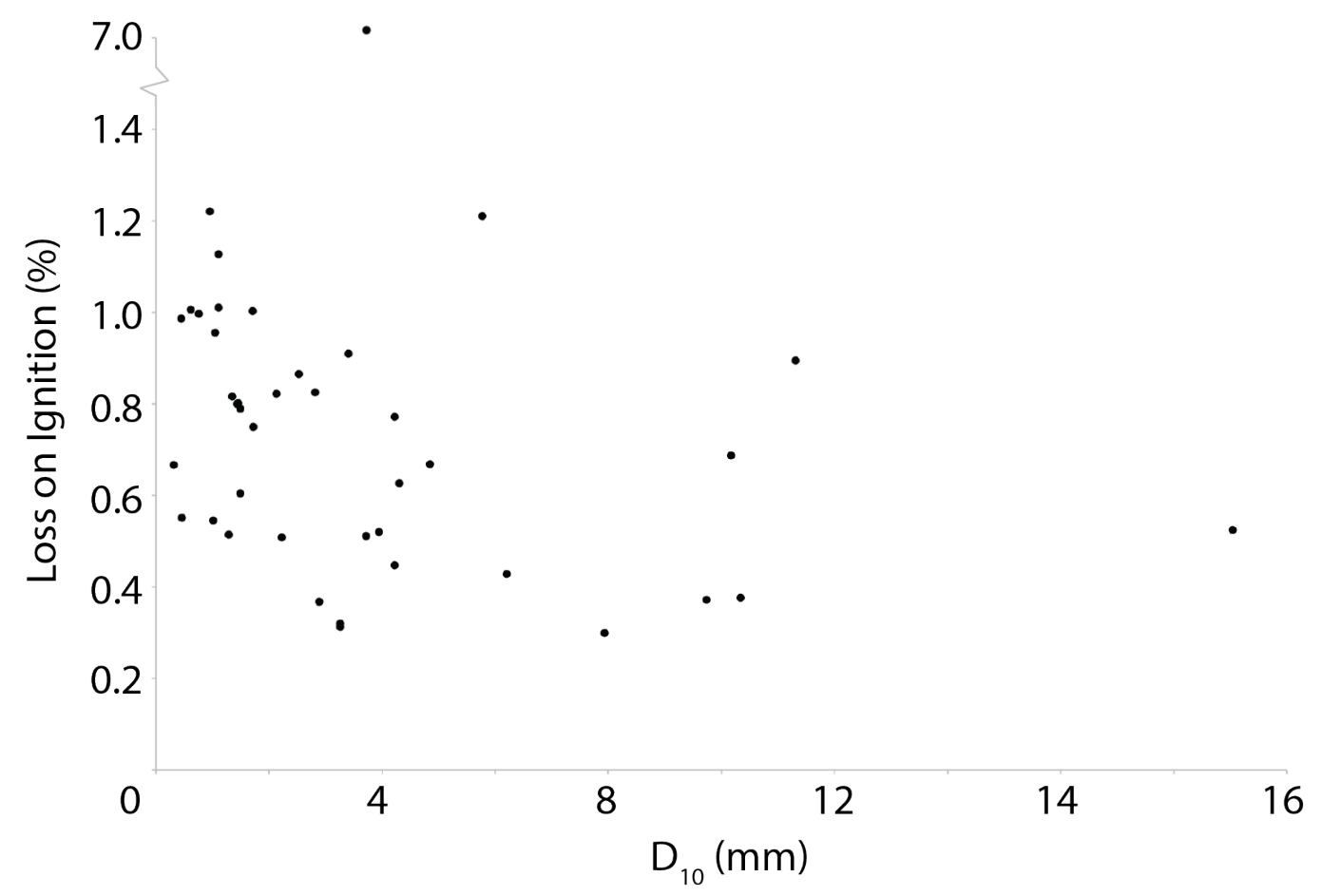


Figure 7: Percent loss on ignition, a proxy for organic matter content, plotted against $\mathrm{D}_{10}$. There is a weak tendency towards more organic matter in finer sediments.

Ground Penetrating Radar Analysis. The GPR survey displays morphological features consistent with pools and riffles along a meandering stream (Figure 8). Variations in water depths on the GPR transects are also qualitatively confirmed in aerial images (Figure 1). Water depths indicate a deep pool at the start of the reach in a relatively straight section of the channel. Moving around the meander on the longitudinal transect, water depths shallow along a riffle. Towards the end of the reach, the riffle starts to deepen into a pool along the bend of the next meander. The channel-perpendicular transects such as typesection A-A' (Figure 3) show the gradual slope of the channel on the point bar edge $(A)$, and the eroding slope on the cut bank (A').



Figure 8: A) Water depth measured by GPR in meters. B) Amplitude measurements collected by GPR.

In the GPR survey, the amplitude of the water bottom reflection also varies along the reach. The recorded amplitudes depend on the dielectric contrast between water and sediment and the thickness of the reflecting boundary (Sharma, 1997). At this site, amplitude does not show a clear relationship with grain size ( $\mathrm{D}_{10}$ values) from the sample nearest the nearest GPR trace (Figure 
9A). Furthermore, there was no relationship between amplitude and potential upwelling or downwelling conditions (see next section).


Figure 9: A) Grain size $\left(\mathrm{D}_{10}\right)$ shows no clear relationship with amplitude of the water bottom measured by GPR. B) Vertical head gradients show no clear relationship with GPR amplitudes.

Potential for Vertical Flow. Vertical head gradient measurements varied throughout the meander and had a mean value of $0.019 \mathrm{~m} / \mathrm{m}$. There is a greater amount of potential upwelling sites than potential downwelling sites. There does not seem to be a clear relationship between $\mathrm{D}_{10}$ values and vertical head gradient (Figure 10). 




Figure 10: Vertical head gradients versus grain size $\left(\mathrm{D}_{10}\right)$. Positive hydraulic head gradients indicate potential upwelling conditions, and negative head gradients indicate potential downwelling conditions.

Spatial patterns of vertical hydraulic head gradients (Figure 11) show general downwelling on the upstream edge of the meander and upwelling downstream, consistent with lateral flow through the meander. A transition from downwelling to upwelling also occurs within the pool on the south end of the reach and along the riffle near the relatively fine-grained point bar. 




Figure 11: Vertical hydraulic head gradient at $20 \mathrm{~cm}$ depth in the streambed. 


\section{Discussion}

In this meander within an alpine stream, the distribution of sediment sizes varied but was overwhelmingly coarse (Figure 6A). Heterogeneity in a meandering streambed has been shown to determine the locations of upwelling and downwelling, particularly in studies with strongly varying sediment types (Cardenas, 2004; Pryshlak et. al., 2015). In our meander, the overall patterns of upwelling and downwelling appear to coincide most clearly with channel morphology, though grain size also likely plays a role. The point bar along the right edge of the channel towards the southern start of the reach is an area of potential downwelling. This downwelling is expected because of the transition from a pool to a riffle at this location (Figure 6A, Figure 8A). Previous studies have demonstrated that stream water downwells into riffles that coincide with an upward slope of the river bed (Harvey and Bencala, 1993; Tonina and Buffington, 2005). The right edge of the channel along the eastern edge of the reach is an area of potential upwelling (Figure 11), as expected where a riffle slopes downward into a pool (Figure 8A). The area with the greatest potential for upwelling conditions lies at the northern apex of the meander and also corresponds with a riffle composed of relatively finer gravels with greater loss on ignition (Figure 6). The finer sediment textures here may impede the flow and allow greater head gradients to develop. In general, patterns of hyporheic exchange appear to be shaped largely by the interactions of currents with the meander and modified by local factors like the slope of the bed and grain size.

Ground-penetrating radar is a useful tool for visualizing the stream bed and interpreting some morphologic features. The growing point bar and eroding cut bank can be seen in Figure 3, and the longitudinal transect displays how the meander's bed slope changes over pool-riffle sequences moving downstream. This morphologic information is essential for creating models of hyporheic exchange (Chow et al., 2018). However, we were not able to observe a correlation between the amplitude measured from the GPR and the grain size data. This lack of correlation is somewhat surprising because Drzewiecki et al. (2010) used amplitudes to identify different rock types from GPR measurements: low amplitude reflectors were interpreted as a clay-rich deposit, high amplitude and continuous reflectors were thought to be fine-grained floodplain deposits, and moderate amplitude and semi-continuous reflectors were interpreted as coarse braided stream deposits. However, their interpretations were made at deeper depths for subsurface reflectors rather than the sediment-water interface. Sambuelli et al. (2009) performed similar longitudinal GPR transects in the Po River in Italy. They did not see clear agreement between GPR amplitudes and their geologic interpretations. Their explanation was the scattering of energy from larger clasts. Since our meander is gravel-dominated, it is possible that much of our amplitude data are noisy due to the number of large boulders, making it more difficult to distinguish a relationship between amplitude and sediment properties at the water bottom. 


\section{Conclusions}

Hyporheic exchange in this coarse alpine stream is predominantly driven by bedforms such as riffles, pools, and meanders. Although sediments are heterogenous both in grain size and organic matter content, they are predominantly gravelly in texture. Spatial variations in sediment texture likely play a secondary role in modifying the patterns of hyporheic flow imposed by current-bedform interactions. Ground-penetrating radar is a useful tool for visualizing the water bottom and characterizing morphologic features within the channel, but the amplitude is not clearly related to grain size and cannot be used to map or predict sediment texture at this site. The combined approach of using GPR surveys to map streambed morphology and collecting sediment samples to determine grain size is labor-intensive but useful for characterizing the controls on hyporheic exchange. The resulting datasets provide important constraints for creating hyporheic flow simulations. Knowledge of where hyporheic exchange occurs in a streambed will give geochemists and microbiologists insight into reactive transport processes that control water quality. 


\section{RECOMMENDATIONS FOR FUTURE WORK}

This study focused on a single meander in a gravel-dominated alpine stream. Larger rivers such as the Colorado River (downstream of the study site) also have meander sequences that are likely to have different grain size distributions and hyporheic flow patterns. Repeating this method in lowergradient meandering rivers might yield further insights into relationships among hyporheic flow, sediment properties, and channel morphology.

Only 43 of the 86 collected sediment samples were analyzed for grain size. The remaining samples could be analyzed in order to create higher resolution $\mathrm{D}_{10}$ maps, and to constrain a possible relationship between vertical head gradient and sediment size. Ground-penetrating radar data were also collected along the meander downstream of Meander A. Sediment samples could be collected in this meander and integrated in the interpretation of the GPR surveys. 


\section{References Cited}

ASTM, D. 2974-87, 1993, Standard test methods for moisture, ash, and organic matter of peat and other organic soils: USA.

ASTM. C136/C136M-14, 2014, Standard Test Method for Sieve Analysis of Fine and Coarse Aggregates: West Conshohocken, PA, ASTM International.

Boano, F., Camporeale, C., Revelli, R., Ridolfi, L., 2006, Sinuosity-driven hyporheic exchange in meandering rivers, Geophysical Research Letters, vol. 33, doi:10.1029/2006g1027630.

Boulton, A.J., Findley, S., Marmonier, P., Stanley, E.H., Valett, H.M., 1998, The Functional Significance of the Hyporheic Zone in Streams and Rivers, Annual Review of Ecology and Systematics, vol. 29, no. 1, p. 59-81, doi:10.1146/annurev.ecolsys.29.1.59.

Cardenas, M.B., and Wilson, J.L., 2007, Hydrodynamics of coupled flow above and below a sediment-water interface with triangular bedforms, Advances in Water Resources, vol. 30, p. 301-313, doi:10.1016/j.advwatres.2006.06.009.

Cardenas, M.B., Wilson, J.L., Zlotnik, V.A., 2004, Impact of heterogeneity, bed forms, and stream curvature on subchannel hyporheic exchange, Water Resources Research, vol. 40, doi:10.1029/2004wr003008.

Chow, R., Wu, H., Bennett, J.P., Dugge, J., Wöhling, T., Nowak, W., 2018, Sensitivity of Stimulated Hyporheic Exchange to River Bathymetry: Steinlach River Test Site, Groundwater, vol. 57, p. 378-391, doi:10.1111/gwat.12816.

Drzewiecki, P., Hyatt, J.A., Oster, W.C., Nicoulin, A., 2010, Abstract, Abstracts with Programs, Boulder, CO, Geological Society of America (GSA), vol. 42, p. 241.

Engdahl, N.B., Volger, E.T., Weissmann, G.S., 2010, Evaluation of aquifer heterogeneity effects on river flow loss using a transition probability framework, Water Resources Research, vol. 46, doi:10.1029/2009wr007903.

Harvey, J.W., and Bencala, E., 1993, The Effect of Streambed Topography on Surface-Subsurface Water Exchange in Mountain Catchments, Water Resources Research, vol. 29, no. 1, p. 89-98, doi:10.1029/92wr01960.

Harvey, J.W., Böhlke, J.K., Voytek, M.A., Scott, D., Tobias, C.R., 2013, Hyporheic zone denitrification: controls on effective reaction depth and contribution to whole-stream mass balance, Water Resources Research, vol. 49, no. 10, p. 6298-6316, doi:10.1029/97wr3606. 
Kiel, B.A., and Cardenas, M.B., 2014, Lateral hyporheic exchange throughout the Mississippi River network, Nature Geoscience, vol. 7, p. 413-417, doi:10.1038/ngeo2157.

Nagorski, S.A., and Moore, J.N., 1999, Arsenic mobilization in the hyporheic zone of a contaminated stream, Water Resources Research, vol. 35, no. 11, p. 3441-3450, doi:10.1029/1999wr900204.

Nelson, A.R., Sawyer, A.H., Gabor, R.S., Saup, C.M., Bryant, S.R., Harris, K.D., Briggs, M.A., Williams, K.H., Wilkins, M.J., 2019, Heterogeneity in Hyporheic Flow, Pore Water Chemistry, and Microbial Community Composition in an Alpine Streambed, Journal of Geophysical Research: Biogeosciences, vol. 124, no. 11, p. 3465-3478., doi:10.1029/2019jg005226.

Pryshlak, T.T., Sawyer, A.H., Stonedahl, S.H., Soltanian, M.R., 2015, Multiscale hyporheic exchange through strongly heterogenous sediments, Water Resources Research, vol. 51, p. 9127-9140, doi: 10.1002/2015WR017293.

Ruhala, S.S., Zarnetske, J.P., Long, D.T., Lee-Cullin, J.A., Plont, S., Wiewiora, E.R., 2018, Exploring dissolved organic carbon cycling at the streamgroundwater interface across a third-order, lowland stream network, Biogeochemistry, vol. 137, no. 1-2, p. 105-126, doi:10.1007/s10533-017-0404$z$.

Sambuelli, L., Calzoni, C., and Pesenti, M., 2009, Waterborne GPR survey for estimating bottom-sediment variability: A survey on the Po River, Turnin, Italy: Geophysics, vol. 74, doi: 10.1190/1.3119262.

Sandmeier, K.J., 2019, REFLEXW, [computer software], Retrieved from: https://www.sandmeier-geo.de/Download/reflexw_manual_a4.pdf.

Saup, C.M., Williams, K.H., Rodrígeuz-Freire, L., Cerrato, J.M., Johnston, M.D., Wilkins, M.J., 2017, Anoxia stimulates microbially catalyzed metal release from Animas River sediments, Environmental Science: Processes Impacts, vol. 19, no. 4, p. 578-585, doi:10.1039/c7em00036g.

Sharma, P.V., 1997, Environmental and engineering geophysics: Cambridge, Cambridge University Press.

Sinsabaugh, R.L., and Findley, S., 1995, Microbial Production, Enzyme Activity, and Carbon Turnover in Surface Sediments of the Hudson River Estuary, Microbial Ecology, vol. 30, no. 2, p. 127-141, doi: $10.1007 /$ bf00172569. 
Stegen, J.C., et al., 2016, Groundwater-surface water mixing shifts ecological assembly processes and stimulates organic carbon turnover, Nature Communication, vol. 7, doi:10.1038/ncomms 11237.

Stonedahl, S.H., Harvey, J.W., Wörman, A., Salehin, M., Packman, A.I., 2010, A multiscale model for integrating hyporheic exchange from ripples to meanders, Water Resources Research, vol. 46, doi:10.1029/2009wr008865.

Tonina, D., and Buffington, J.M., 2007, Hyporheic exchange in gravel bed rivers with pool-riffle morphology: Laboratory experiments and threedimensional modeling, Water Resources Research, vol. 43, p. 1-16, doi: 10.1029/2005wr004328.

Winter, T.C., Harvey, J.D., Franke, O.L., Alley, W.M., 1998, Ground Water and Surface Water: A single resource, U.S. Geological Survey Circular, vol. 7, no. 1139, p. 79 , doi: $10.3133 / \operatorname{cir} 1139$

Wondzell, S.M., 2006, Effect of morphology and discharge on hyporheic exchange flows in two small streams in the Cascade Mountains of Oregon, USA, Hydrological Processes, vol. 287, p. 267-287, doi:10.1002/hyp.5902. 


\section{Appendix A}

\section{Grain Size Analysis Standard Operating Procedure}

1. Allow sediment samples to air dry completely on plastic or metal trays. Allow the Whirly bag to air dry as well to retrieve finer sediments still inside.

2. Once dry, break up any clumps of rock and sediment. Then slowly pour the sediment sample onto the center of a piece of paper. Turn the paper as you are pouring to create an evenly distributed cone or pyramid of sediment.

3. Divide the cone of sediment into representative quarters using your best judgement.

4. Take one quarter of the sediment and place in a pre-weighed ceramic dish. Mass the sample and then bake it at $105^{\circ} \mathrm{C}$ for at least 16 hours to evaporate any remaining water. Mass again and place the sample back in the oven at $105^{\circ} \mathrm{C}$ for another 4 hours. Repeat this process until there is no change in mass (ensures all water has been evaporated out).

5. Place the sample in a muffle furnace at $440{ }^{\circ} \mathrm{C}$ for 4 hours and let the sample cool in the furnace overnight. Mass the sample again quickly, and at a consistent time for each sample, to prevent the sample from rehydrating. The difference in mass is attributed to the combustion of organic matter in the sample.

6. The three quarters of sediment sample remaining after step 3 are wet sieved using a $63 \mu \mathrm{m}$ sieve. The coarse fraction is placed in a glass beaker and baked at $105{ }^{\circ} \mathrm{C}$ to evaporate the water.

7. The water used to wet sieve is caught and placed in $1000 \mathrm{~mL}$ graduated cylinders in order to estimate the fines $(<63 \mu \mathrm{m})$ content. Top the water level off at $1000 \mathrm{~mL}$ in the graduated cylinder and stir vigorously for at least 30 seconds. Then, using a $5 \mathrm{~mL}$ pipette, extract $20 \mathrm{~mL}$ total of the sample from the $750 \mathrm{~mL}$ mark on the cylinder, stirring before every $5 \mathrm{~mL}$ taken out. Place the $20 \mathrm{~mL}$ of muddy water onto a pre-weighed aluminum tin and bake at $105{ }^{\circ} \mathrm{C}$ to evaporate the water. Mass the tin after baking. Calculate the estimated fines mass contribution by:

(Baked tin weight $(\mathrm{g})$ - Empty tin weight $(\mathrm{g})) * 50$

8. After the sediment sample from step 6 is dried, dry sieve the sample using the following sieve stack from top to bottom: $25400 \mu \mathrm{m}$ (1 inch), $19000 \mu \mathrm{m}(3 / 4$ inch), $9500 \mu \mathrm{m}(3 / 8$ inch), $4750 \mu \mathrm{m}$ (ASMT No. 4), $2360 \mu \mathrm{m}$ (ASMT No. 8), $1180 \mu \mathrm{m}$ (ASMT No. 16), $600 \mu \mathrm{m}$ (ASMT No. 30), $300 \mu \mathrm{m}$ (ASMT No. 50), $150 \mu \mathrm{m}$ (ASMT No. 100), $75 \mu \mathrm{m}$ (ASMT No. 200), and a pan. Because of the coarseness and size of the sample, 10 inch diameter sieves had to be used. Each sieve stack was placed on a Ro-tap for 10 minutes to insure complete grain separation. Then, working from the top of the stack down, each sieve's contents were poured onto a tray and remaining grains were removed using a brush and then massed in a pre- 
weighed ceramic dish. Each sieve's mass contribution was divided by the mass of the total sample in order to find the mass fraction.

9. The fines mass contribution and the dry sieve grain size data are then compiled to represent the entire sample. 